\title{
University Students' Conceptions of Mathematical Symbols and Expressions
}

\author{
Kin Eng Chin ${ }^{1 *}$, Robyn Pierce ${ }^{2}$ \\ ${ }^{1}$ Flinders University, AUSTRALIA \\ 2 Melbourne Graduate School of Education, The University of Melbourne, AUSTRALIA \\ Received 30 November 2018 - Revised 5 February 2019 - Accepted 5 February 2019
}

\begin{abstract}
Undergraduate mathematics instructors often report that students make careless errors or have not previously learned key mathematical ideas and strategies. The purpose of this study is to explore evidence of an alternative explanation that at least some of these "errors" may result from students' application of conceptions developed in the narrower contexts of their earlier learning. Analysis of formal printed lecture notes, student work and questionnaire responses is performed. Data collected from two Australia Universities' first year mathematics students are reported in this paper that explores respondents' conceptions related to symbolic mathematical expressions in different contexts by using the survey research design. The data were analysed through two lenses in order to both identify likely supportive and problematic conceptions and also distill the aspects of symbolic expressions contributing to this classification. The findings show that students' errors patterns are associated to problematic conceptions that might arise from contexts previously encountered by students. More than $50 \%$ of the recorded errors related to $\sin ^{-1}(x)$ by University 1 students are linked to problematic conceptions. This study is significant because it shows that it is important to explicitly address such potentially problematic conceptions in order to help students bridge the transition between contexts and this may be done through lecture notes.
\end{abstract}

Keywords: mathematical errors, prior learning, problematic conception, supportive conception, symbolic expression

\section{INTRODUCTION}

The declining enrolments in mathematics courses at Australian universities is a major concern across the nation (Chubb, Findlay, Du, Burmester, \& Kusa 2012) and was the impetus for a research project from which the data in this paper was drawn. This phenomenon has serious impacts to the quality of Australia workforce. According to Singhal (2018, March 24), an Australia newspaper article published by The Sydney Morning Herald stated that the decline enrolments would cause Australia to leave behind other countries because Australians don't have the data analysis and the technical skills for the future. On top of that, the decline of the effect is also visible in students' performances in international tests such as the Trends in International Mathematics and Science Study (TIMMS) and the Programme for International Student Assessment (PISA). Mathematics is central to Science, Technology and Engineering thus these declining enrolments would impede Australia from producing the necessary STEM labor force. Due to the importance of this issue, we wish to explore the possible root causes for this phenomenon. We speculate that this might be due to the complexity in comprehending mathematical symbols that lead students to avoid taking mathematics courses. The project examined undergraduate students' working in the increasingly symbolic environment of university mathematics (Bardini, Pierce \& Vincent, 2015). Based on Pimm (1991), symbols are used to demonstrate the structure of mathematics, they allow manipulations to become routine, and allow mathematics to be expressed and recorded compactly. According to the respected USA National Council of Teachers of Mathematics (NCTM, 2000), when students learn mathematics with understanding, they actively build

(C) 2019 by the authors; licensee Modestum Ltd., UK. This article is an open access article distributed under the terms and conditions of the Creative Commons Attribution License (http://creativecommons.org/licenses/by/4.0/). \kineng.chin@flinders.edu.au (*Correspondence) $\$ r.pierce@unimelb.edu.au 


\section{Contribution of this paper to the literature}

- This study fills in a research gap that focuses on identifying students' problematic conceptions related to mathematical symbols in their undergraduate mathematics subject.

- This study highlights the importance of mathematical domains or contexts in teaching and learning of mathematics.

- Findings indicate that there is a pattern of students' errors in making sense of mathematical symbols and this pattern is based on individual conceptions that are developed through prior learning.

new knowledge from experience and prior knowledge. However, it does not specify how exactly this connection of new and prior knowledge can be achieved. Based on the survey responses collected from 125 teacher educators and experienced teachers, Sullivan and Mousley (2005) discovered that building understanding was one of the six major components of quality mathematics teaching. This study further revealed that prior knowledge was one of most important ingredients for building understanding.

According to NCTM (2009), "sense making may be considered as developing understanding of a situation, context, or concept by connecting it with existing knowledge or previous experience" (p.4). Thus, the act of introducing new mathematical concepts without helping students to make appropriate connections to their prior experiences might not help the students make sense of the new concepts and this could lead to incomplete understanding.

\section{SUPPORTIVE AND PROBLEMATIC CONCEPTIONS}

Sophisticated mathematical thinking builds on personal interpretations of mathematical concepts. The question is, what is a conception? Sfard (1991) described a conception as "the whole cluster of internal representations and associations evoked by the concept - the concept's counterpart in the internal, subjective universe of human knowing" (vol 22, p.3). Similarly, Tall and Vinner (1981) proposed the term concept image to indicate the total cognitive structure associated with a concept which might include mental images, representations, processes and properties. In addition they used the notion of concept definition to refer to a form of words used to specify the concept. While there is mathematics register that is agreed on by the mathematics community, in reality learners will make sense this concept based on personal conceptions which are based on experience and are subjective in nature, thus a standardized form of understanding is hard to achieve across different learners. We posit that the spectrum of students' responses in making, or not making, sense of mathematical concepts is partly due to their subjective response to prior experiences. The more able learners will make sense of new mathematical ideas based on the conceptions that they hold. From their prior understanding they build a more sophisticated knowledge structure taking into account the restrictions of a new context. On the other hand, the less able learners tend to learn new ideas as disparate facts that are not connected to previous learning (Tall, 2013).

This sparks an interesting question of how do humans acquire mathematical conceptions. Based on Smith, Disessa and Roschelle (1993), one of the dominant ingredients that shape our conceptions is prior experience. According to constructivists, humans construct knowledge and meaning from their past experiences and this needs to be guided by a mentor, rather than only being transmitted (Tall, 2013). Prior experiences are an important foundation for sense-making therefore Lima and Tall (2008) introduced the term met-before to indicate the effect of previous experience in a new situation that affects our current thinking. It should be noted that met-befores shape our conceptions. As a result humans may have either supportive conceptions or problematic conceptions impacting on their sense making in a new situation.

According to Chin and Tall (2012) and Chin (2013), supportive conceptions refer to those conceptions that work in an old context and continue to work in a new context. On the other hand, problematic conceptions indicate those conceptions that work in an old context and do not work, without refinement, in a new context. These notions are useful for us to describe instances that involve the transition from one context to another. In particular, personal conceptions can be a support or barrier for making sense of a new situation. As an illustration, sometimes the multiplication symbol $(\times)$ is interpreted as "repeated addition" when it involves the natural numbers. For instance, $2 \times 3$ is read as "two groups of three" so $2 \times 3=3+3$. This will lead students to have a conception that multiplication is repeated addition. When the students move to another situation which involves the multiplication of whole numbers, this conception still holds thus repeated addition is a supportive conception in this new situation. However when the students encounter the multiplication in the new context of fractions, the conception of repeated addition is problematic because it doesn't make sense to interpret the familiar multiplication symbol $(\times)$ as repeated addition. For example, $\frac{1}{2} \times \frac{1}{3}$ can be read as $\frac{1}{2}$ of $\frac{1}{3}$. Now the multiplication symbol $(\times)$ has to be interpreted in this new situation as "of". In this case, repeated addition is a problematic conception because it 


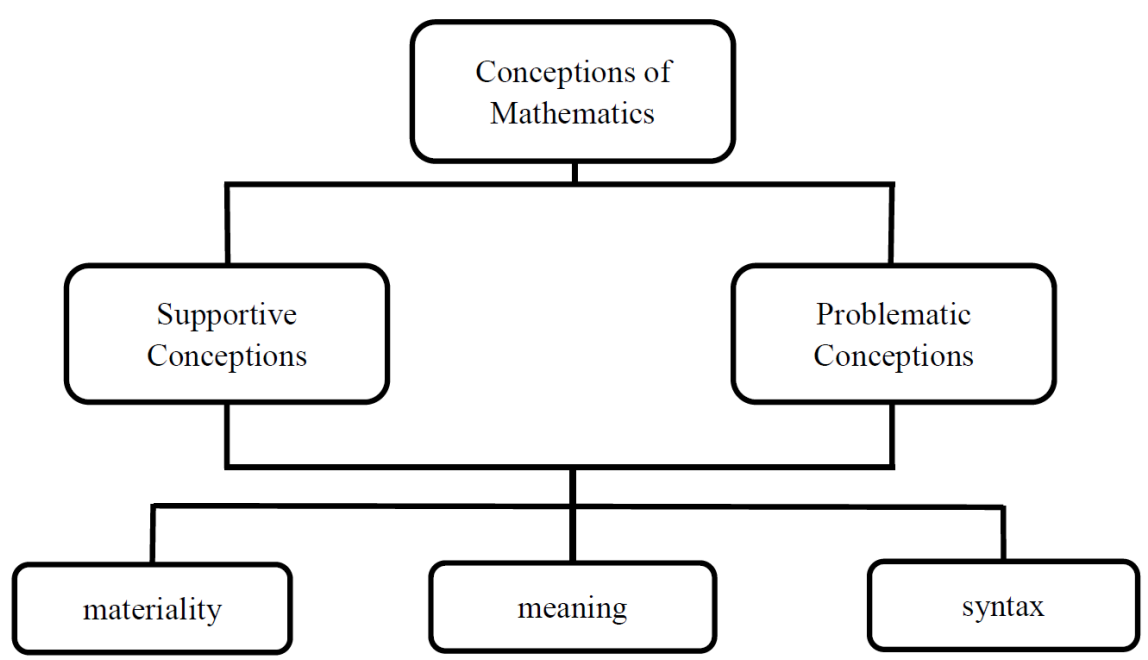

Figure 1. Theoretical Framework

impedes the sense-making of the students. In short, supportive conceptions support generalization in a new situation whereas problematic conceptions may impede progress (Chin, 2014).

\section{THREE ASPECTS OF A SYMBOL: MATERIALITY, SYNTAX AND MEANING}

In mathematics, concepts are commonly represented symbolically. It may be helpful to analyse the interpretation of symbolic expressions to order to identify potential problems. According to Bardini, Pierce and Vincent (2015), a particular symbol can be examined from three aspects namely materiality, syntax and meaning. In this case, "materiality" refers to the appearance of a symbol and this can be a Latin or Greek letter, or an operator and its physical attributes. For instance, the letter $i$ is used to denote the "imaginary" part of a complex number. "Syntax" means the position and the conventions associated with a particular symbol. Take for instance the operator $\times$ that must have some symbol or expression on either side of it. Sherin (1996) proposed the notion of symbol template to describe the syntactical aspect of mathematical expressions. Today, mathematical and word processing software often supply common syntax templates. The third aspect is "meaning" which refers to the meaning of a symbol in a context. For example the multiplication symbol $(x)$ in $2 \times 3=3+3$ can be interpreted as repeated addition however it must be interpreted as "of" for the case of $\frac{1}{2} \times \frac{1}{3}=\frac{1}{6}$. When the multiplication symbol $(\times)$ is involved in a real world problem that comprises of unit length such as $2 \mathrm{~cm} \times 3 \mathrm{~cm}=6 \mathrm{~cm}^{2}$, then the product will become an area. This shows that the various meanings of the multiplication symbol are context dependent. Building on the framework Bardini and Pierce (2015) proposed the notion of symbol load in order to focus on the students' experience of the changes in symbols, their frequency, use, and various meanings as they progress in mathematics.

\section{THEORETICAL FRAMEWORK}

We employed a two-stage analysis for the data by using two different frameworks (see Figure 1). The reason of doing this was because we wanted to have a more detailed analysis of the data. On top of that, both frameworks had their own strengths thus they could complement each other. At the first stage, we used the framework of supportive and problematic conceptions as proposed by Chin and Tall (2012) and Chin (2013) to highlight how the transitions of contexts may have an impact on students' conceptions of symbols. Then we employed the framework of Bardini, Pierce and Vincent (2015) based on Serfati (2005) which emphasized the three aspects of a symbol, namely materiality, syntax and meaning so that we can identify likely sources of confusion.

\section{METHODOLOGY}

In general, the main purpose of this study is to explore students' errors in understanding mathematical symbols. Additionally it also searches for evidence that could indicate how these errors arise. This study employed a survey research design in order to gather opinions from a big sample. Two groups of first year mathematics undergraduate students from two different Australia universities were involved in this study. A set of questionnaires is used to collect the relevant data. In this paper, we analyse students' responses to selected items from one of the questionnaires used for the bigger project and the title of the project is "Secondary \& University mathematics: Do 
Table 1. University 1 Students' interpretations of superscript $-1(n=100)$

\begin{tabular}{|c|c|c|c|c|c|}
\hline$x^{-1}$ & $\begin{array}{c}\% \\
\text { of students }\end{array}$ & $\sin ^{-1}(x)$ & $\begin{array}{c}\% \\
\text { of students } \\
\end{array}$ & $f^{-1}(x)$ & $\begin{array}{c}\% \\
\text { of students } \\
\end{array}$ \\
\hline$\frac{1}{x}$ & 68 & $\arcsin (x)$ & 41 & $f^{-1}(x)=\frac{x-1}{3}$ & 37 \\
\hline Reciprocal of $x$ & 12 & or $\operatorname{cosec}(x)$ & 41 & $\frac{1}{3 x+1}$ & 17 \\
\hline Inverse $\left(\frac{1}{x}\right)$ & 5 & Reciprocal & 9 & Inverse of $f(x)$ & 28 \\
\hline To the power -1 & 6 & Not $(\sin x)^{-1}$ & 1 & Derivative & 3 \\
\hline Other response & 7 & Inverse $\sin x$ & 0 & Integral & 3 \\
\hline \multirow[t]{2}{*}{ Missing/ no idea } & 2 & Other response & 3 & Other response & 7 \\
\hline & & Missing/ no idea & 5 & Missing/ no idea & 5 \\
\hline
\end{tabular}

they speak the same language?" (Bardini, Pierce \& Vincent, 2015; Pierce \& Bardini, 2016). The data was first collected to examine factors leading to a change in symbol load for between school and university. We reanalyzed this data with the purpose of addressing the following research questions:

- What are the observed problematic conceptions in making sense of $f^{-1}(x)$ ?

- What are the observed problematic conceptions in making sense of $\sin ^{-1}(x)$ ?

- What are the observed problematic conceptions in making sense of multiplication of vectors?

- Is there evidence showing that the Universities' lecture notes draw attention to the possible problematic conceptions?

- What are the possible problematic conceptions not explicitly mentioned in the lecture notes?

For this project, data has been collected from staff and students at two Australian universities. These universities have a variety entrance requirements and students, both Australian and international, come from diverse range of backgrounds. All respondents were studying a first year mathematics subject that required them to have previously studied some one-variable calculus, vectors and probability.

All the data presented in this particular paper were collected from University 1 (Study 1) and University 2 (Study 2) through two different surveys (Survey 1 and Survey 2). These surveys are two different questionnaires that comprise of mathematical expressions. We also collected the lecture notes provided to students studying Subject 1 (University 1) and Subject 2 (University 2). These subjects were similar and both had the prerequisite of VCE Mathematics Methods (VCAA, 2016). Thus the respondents were expected to have previously studied topics such as negative exponents, functions and trigonometric functions.

The respondents were volunteers and hence it was a convenience sample. This sampling method was used due to budget, time and resources issues that wouldn't allow the researchers to create a large and randomized sample. One of the purposes for administering the surveys was to explore the conceptions of the respondents related to particular mathematical symbols or expressions. The lecture notes were analysed by using the proposed theoretical framework (see Figure 1) to look for any association between those lecture notes and the students' responses in the surveys. Additionally, we also looked for evidence in the lecture notes of sections addressing possible problematic conceptions.

\section{RESULTS AND DISCUSSION}

\section{Survey 1 Example: Superscript "-1"}

The data presented in Table 1 which is also reported in Pierce and Bardini (2016) was collected through Survey 1 from University 1. In Survey 1, the students were asked to "explain the meaning of -1 for $x^{-1}$, $\sin ^{-1}(x)$ and $f^{-1}(x)$ where $f(x)=3 x+1$ ". The same question was put to students at University 2 and their responses are summarized in Table 2.

In Table 3 and Table 4 we present analysis of the content for University 1 and University 2 lecture notes for sections related to this item in Survey 1 . We analysed these topics related to the symbols $x^{-1}, f^{-1}$ and $\sin ^{-1}$ in order to trace possible conceptions that might arise from other contexts, but which, if not modified become problematic in a new context and may trigger students' incorrect responses as shown in Tables $\mathbf{1}$ and 2. Note also that trigonometric functions are part of the prerequisite knowledge students should have covered in VCE Mathematical Methods (VCAA, 2016) (or equivalent). 
EURASIA J Math Sci and Tech Ed

Table 2. University 2 Students' interpretations of superscript $-1(n=100)$

\begin{tabular}{|c|c|c|c|c|c|}
\hline$x^{-1}$ & $\begin{array}{c}\% \\
\text { of student }\end{array}$ & $\sin ^{-1}(x)$ & $\begin{array}{c}\% \\
\text { of students }\end{array}$ & $f^{-1}(x)$ & $\begin{array}{c}\% \\
\text { of students }\end{array}$ \\
\hline 1 & \multirow{2}{*}{43} & \multirow{2}{*}{$\arcsin (x)$} & \multirow[t]{2}{*}{3} & \multirow{2}{*}{$f^{-1}(x)=\frac{x-1}{3}$} & \\
\hline $\bar{x}$ & & & & & 31 \\
\hline \multirow{2}{*}{ Reciprocal of $x$} & \multirow{2}{*}{21} & \multirow{2}{*}{$\frac{1}{\sin (x)}$ or $\operatorname{cosec}(x)$} & \multirow{2}{*}{10} & 1 & \\
\hline & & & & $\overline{3 x+1}$ & 2 \\
\hline Inverse of $x$ & 2 & Reciprocal & 0 & Inverse of $f(x)$ & 63 \\
\hline To the power -1 & 34 & Inverse of $\sin (x)$ & 73 & $f^{-1}(x)=3 y+1$ & 2 \\
\hline Other response & 0 & Undoing of $x$ & 2 & Derivative & 0 \\
\hline \multirow{5}{*}{ Missing/ no idea } & \multirow{5}{*}{0} & To the power of -1 & 2 & Integral & 0 \\
\hline & & Sine inverse of $x$ & 2 & Other response & 2 \\
\hline & & $\frac{x}{\sin }$ & 2 & Missing/ no idea & 0 \\
\hline & & $\frac{\text { sin }}{\text { Other response }}$ & 3 & & \\
\hline & & Missing/ no idea & 3 & & \\
\hline
\end{tabular}

Table 3. Analysis of lecture notes in relation to Survey 1

\begin{tabular}{|c|c|c|c|}
\hline $\begin{array}{l}\text { Order in the } \\
\text { lecture notes } \\
\text { (section) }\end{array}$ & Main idea & $\begin{array}{l}\text { Description of lecture notes / Explanation given in the lecture } \\
\text { notes }\end{array}$ & $\begin{array}{l}\text { Possible problematic } \\
\text { conception(s) }\end{array}$ \\
\hline \multirow{2}{*}{1} & $\begin{array}{l}\text { Sine function } \\
\text { (Subject 1) }\end{array}$ & $\begin{array}{l}\sin (\theta)=\frac{o p p}{h y p} \text { in the context of triangle trigonometry. } \\
\sin (\theta) \text { in the context of unit circle. }\end{array}$ & No identified \\
\hline & $\begin{array}{l}\text { Functions } \\
\text { (Subject 2) }\end{array}$ & $\begin{array}{l}\text { A function } f: A \rightarrow B \text { is a rule that assigns to each element } x \text { in set } A \\
\text { a unique element } y=f(x) \text { in set } B \text {. }\end{array}$ & No identified \\
\hline \multirow[b]{2}{*}{2} & $\begin{array}{l}\text { Cosecant function } \\
\text { (Subject 1) }\end{array}$ & $\begin{array}{l}\text { The reciprocal of the sine function is called the cosecant function. } \\
\operatorname{cosec}(x)=\frac{1}{\sin (x)} \\
\sin (x) \neq 0\end{array}$ & $\sin ^{-1}(x)=\frac{1}{\sin (x)} ?$ \\
\hline & $\begin{array}{l}\text { Inverse functions } \\
\text { (Subject 2) }\end{array}$ & $\begin{array}{l}\text { Two functions are inverses of each other if each of them 'undoes' } \\
\text { what the other one 'does'. If a function } f \text { does happen to have an } \\
\text { inverse function over a particular domain then we write that } \\
\text { function as } f^{-1} \text {. } \\
\text { Do not interpret the " }-1 \text { " in } f^{-1} \text { as a power/exponent: the notation } \\
f^{-1}(x) \text { does not mean } \frac{1}{f(x)} \text { ! }\end{array}$ & No identified \\
\hline \multirow{2}{*}{3} & $\begin{array}{l}\text { Inverse function } \\
\text { (Subject 1) }\end{array}$ & $\begin{array}{l}\text { If } f: X \rightarrow Y \text { is a function, then inverse function of } f \text { is a function } \\
g: Y \rightarrow X \text { such that } \\
g(f(x))=x \text { for all } x \in X \text { and } f(g(y))=y \text { for all } y \in Y\end{array}$ & $f^{-1}(x)=\frac{1}{f(x)} ?$ \\
\hline & $\begin{array}{l}\text { Sine function } \\
\text { (Subject 2) }\end{array}$ & $\begin{array}{l}\sin x=\frac{o p p \text { side }}{\text { hypotenuse }} \text { with reference to a right angled triangle in a unit } \\
\text { circle. }\end{array}$ & No identified \\
\hline \multirow[t]{2}{*}{4} & $\begin{array}{l}\text { Inverse sine function } \\
\text { (arcsine) } \\
\text { (Subject 1) }\end{array}$ & $\begin{array}{l}\text { Restrict the domain of sine function so that it is one-to-one } \\
\text { function on this restricted domain. (An example of inverse sine } \\
\text { function is shown graphically). This function is called arcsine } \\
\text { (denoted arcsin). }\end{array}$ & $\begin{array}{l}\arcsin =\sin ^{-1}(x) ? \\
\sin ^{-1}(x)=\frac{1}{\sin (x)} ?\end{array}$ \\
\hline & $\begin{array}{l}\text { Sine curve } \\
\text { (Subject 2) }\end{array}$ & The sine graph was presented. & No identified \\
\hline \multirow[t]{3}{*}{5} & $\begin{array}{l}\text { Notation for } \operatorname{Sin}^{-1}(x) \\
\text { and } \frac{1}{\sin (x)} \\
\text { (Subject } 1)\end{array}$ & $\begin{array}{l}\arcsin =\operatorname{Sin}^{-1}(x) \text { where the capital } \mathrm{S} \text { denotes the restricted } \\
\text { domain and the index }-1 \text { means inverse rather than reciprocal. In } \\
\text { this subject we will only use the arcsin notation. This avoids } \\
\text { potential confusion between } \operatorname{Sin}^{-1}(x) \text { and } \frac{1}{\sin (x)}\end{array}$ & $\begin{array}{l}\operatorname{Sin}^{-1}(x)=\sin ^{-1}(x) ? \\
\sin ^{-1}(x)=\frac{1}{\sin (x)} ? \\
\arcsin =\sin ^{-1}(x) ?\end{array}$ \\
\hline & & & $f^{-1}(x)=\frac{1}{f(x)} ?$ \\
\hline & $\begin{array}{l}\text { Inverse sine function } \\
\text { (Subject 2) }\end{array}$ & $\begin{array}{l}\text { The sine curve with domain }-\frac{\pi}{2} \leq x \leq \frac{\pi}{2} \text { and the inverse function } \\
\sin ^{-1} \text { curve were presented. The inverse function } y=\sin ^{-1} x \text { is } \\
\text { sometimes called } \arcsin x \text {. }\end{array}$ & $\sin ^{-1}(x)=\frac{1}{\sin (x)} ?$ \\
\hline 6 & $\begin{array}{l}\text { Cosecant function } \\
\text { (Subject 2) }\end{array}$ & $\begin{array}{l}\text { The cosecant function } \operatorname{cosec} x \text { is defined as the reciprocal of } \sin x \\
\text { that is } \operatorname{cosec} x=\frac{1}{\sin x} \text { for } x \neq n \pi \text { where } n \text { is any integer }\end{array}$ & $\begin{array}{l}\sin ^{-1}(x)=\frac{1}{\sin (x)} ? \\
\sin ^{-1}(x)=\operatorname{cosec} x ?\end{array}$ \\
\hline
\end{tabular}




\section{Survey 1 data from university 1 and university 2}

Most University 1 respondents (80\%) interpreted $x^{-1}$ correctly as either $\frac{1}{x}$ or the reciprocal of $x$ while $5 \%$ gave a mixed message by naming it as "inverse $\left(\frac{1}{x}\right)$ ". For $\sin ^{-1}(x), 44 \%$ interpreted it as $\arcsin (x)$ which was correct. However $50 \%$ of University 1 respondents incorrectly interpreted it as either $\frac{1}{\sin (x)}$ or reciprocal. All the students had met $x^{-1}$ prior to meeting $\sin ^{-1}(x)$ thus the students appeared to transfer the meaning of negative exponents met-before in real numbers to the context of trigonometric functions. 62 students responded that " -1 " means " 1 over", for example " $\frac{1}{\sin (x)}$ ". The conception of negative exponents such as -1 can be interpreted as " 1 over something" in the context of real numbers is regarded as a problematic conception in the context of functions because this conception does not work in this new context. The issue was these respondents were not aware of this problematic conception. They focused on the aspects of the materiality of the syntax template ${ }^{-1}$ and blindly transferred what they learned from the previous context to a new context thus they conceived $\sin ^{-1}(x)$ as if the statement was $[\sin (x)]^{-1}$. In terms of materiality, $x^{-1}$ and $\sin ^{-1}(x)$ appeared similar when referring to the negative exponent (i.e. -1). It appears that these incorrect respondents have focused on the familiar aspects without being aware of the impact of the changes of contexts and the materiality of the compound symbols. The materiality of $x^{-1}$ and $\sin ^{-1}(x)$ can be seen as different if the students perceive the differences in syntax and so conceive them as two compound symbols with different bases. In either case the meaning of " -1 " as a superscript is different.

For $f^{-1}, 37 \%$ of University 1 respondents interpreted it as $\frac{x-1}{3}$ which was correct. In addition $28 \%$ conceived $f^{-1}$ as the inverse of $f(x)$ however some of them had interpreted the notion of inverse function wrongly by responding that the inverse function of $f(x)$ is $\frac{1}{3 x+1}$. Interestingly, given their prior mathematical experience, $17 \%$ of students responded incorrectly by interpreting $f^{-1}$ as $\frac{1}{3 x+1}$, which is the reciprocal of $f(x)$. This might be a S1 response that operates at a non-analytic or intuitive level. According to Leron and Hazzan (2006) there are two types of response namely S1 response and S2 response. In this case, S1 response is immediate and inflexible whereas $\mathrm{S} 2$ response operates at an analytic level which is slow, effortful and relatively flexible. These respondents seemed unaware of the changes of meanings and the syntax of the compound symbol. It might be a S1 response. They transferred their interpretation of negative exponents in real numbers to the context of functions and hence assign superscript -1 the restricted meaning of multiplicative inverse. These results were consistent with Quinnell and Carter (2012) which highlighted that the meanings attached to mathematical symbols made them difficult for students to understand. On top of that, Quinnell and Carter (2012) also claimed that the way in which symbols were used also led to the complexities in comprehending symbols.

When comparing the results shown in Tables 1 and 2 we can notice that University 2 respondents had the higher percentage of correct responses for $x^{-1}, \sin ^{-1}(x)$ and $f^{-1}(x)$. This sparks an interesting question of why this might be so. We analysed the collected lecture notes of University 1 (Subject 1 ) and University 2 (Subject 2) in order to look for possible root causes for these phenomena.

As shown in Table 3, for the Subject 1 lecture notes there were some hidden potentially problematic conceptions related to the interpretation of -1 as superscript. As an illustration, when the lecture notes state that the reciprocal of sine function $\left(\frac{1}{\sin (x)}\right)$ was the cosecant function it did not mention whether the inverse sine function was the reciprocal sine function or not. The survey results indicate that some students may infer that $\sin ^{-1}(x)=\frac{1}{\sin (x)}$ in the same way as the previously encountered $x^{-1}=\frac{1}{x}$. The notes stated the idea of inverse function but did not show the inverse function symbolically as $f^{-1}(x)$ thus the students might conceive $f^{-1}(x)$ as $\frac{1}{f(x)}$, again due to their prior experience with negative exponents. The inverse sine function was introduced and denoted as arcsine. Again in this section, we can notice that there were some hidden potential problematic conceptions, such as the relationships between $\arcsin , \sin ^{-1}(x)$ and $\frac{1}{\sin (x)}$, that were not mentioned explicitly.

The introduction of capital $S$ to denote the restricted domain for sine function was also potentially problematic. However, many mathematics reference books use $\sin ^{-1}$ to represent the inverse sine function thus the use of capital $\mathrm{S}$ in the lecture notes may cause confusion. The lecture notes did not explain the differences between $\operatorname{Sin}^{-1}(x)$ and $\sin ^{-1}(x)$. Although the lecture notes did emphasize that capital $S$ was to represent the restricted domain for sine function this left the student to fill the gaps in making sense how $\operatorname{Sin}^{-1}(x)$ was related to $\sin ^{-1}(x)$ i.e. in order for a sine function to have an inverse function, the domain of sine function must be restricted so that it is a one to one function. Thus whenever we are thinking of the inverse sine function, the domain of its sine function must be restricted.

Based on the analysis of Subject 2 lecture notes (Table 3), there was evidence showing that the $f^{-1}$ notation was explained in a manner that could avoid the problematic conception arose from the learning of negative exponents 


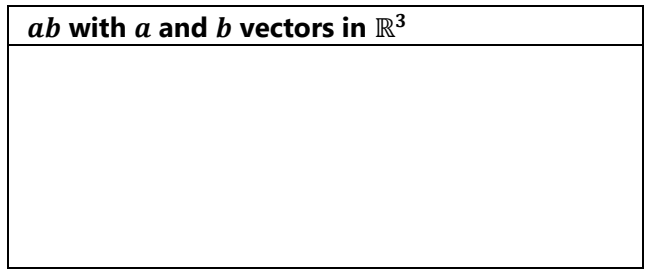

Figure 2. Items in Survey 2

in Real numbers (see section 2 of Subject 2 in Table 3). According to Herbel-Eisenmann and Wagner (2007), language used in textbooks reflects the authors' sense of an ideal pedagogical situation and influences the development of mathematical thinking in situations involved in the text. Based on section 2 of Subject 2 in Table 3, we can see that the lecturer has expressed the mathematics $\left(f^{-1}(x) \neq \frac{1}{f(x)}\right)$ that he hoped (or assumed) the students will construct. This indicates that the lecturer was aware of the problematic conception that may arise from the learning of negative exponents in real numbers.

Based on the analysis presented in Table 3, we can see that some potentially problematic conceptions are not explicitly identified or addressed in the Subject 1 lecture notes. Take for instance, is $f^{-1}(x)$ equal to $\frac{1}{f(x)}$ ? In the lecture notes, the notation $f^{-1}(x)$ did not appear at all. While not addressed in the lecture notes, lecturers could reasonably have assumed that students had met most of these concepts in their prerequisite mathematics and so lecturers do not want to spend time re-teaching. However without some explicit reminders or warning flags in the notes it is clear that many of the respondents have responded incorrectly in Survey 1. From Table 3, we also notice that respondents might have accumulated those possible problematic conceptions while they were studying the lecture notes because those possible problematic conceptions were not addressed explicitly, or at least flagged, at the appropriate sequence or timing in the notes. The finding is consistent with Barton and Heidema (2002) and Shuard and Rothery (1988) (as cited in Shepherd, Selden \& Selden, 2012) which claimed that the writing style of mathematics textbooks usually cause student difficulties.

\section{Survey 2 Example: Vectors vs Real Numbers}

In Survey 2 students were asked to consider the meaning of the symbols $a$ and $b$ in different mathematical contexts. Figure 2 shows the two items that were used. The first item shown in Figure 2 was used to capture respondents' conceptions of real numbers and vectors. All the respondents had studied those topics and had experience in operating with them when completing tutorial exercises. We aimed to explore whether the respondents were able to utilize their particular experiences to make sense of general situations and unfamiliar situations. Additionally, we also looked for patterns of responses. The second item was used to gain an understanding of how the respondents made sense of the two given expressions. The responses of Survey 2 collected from University 1 and University 2 are summarised in Table 4.

i. Tick all the cells for which the following expressions always make sense, depending on the nature of $a$ and $b$.

\begin{tabular}{cc}
\hline & $a$ and $b$ real numbers \\
\hline $2 a-b$ & \\
\hline$a b$ & \\
\hline$a+3$ & \\
\hline$a \geq b$ & \\
\hline
\end{tabular}

ii. For each of the following cases, if you ticked that expression makes sense, give an example for $a$ and $b$, and provide the outcome of the computation.

\section{Survey 2 data from university 1 and university 2}

Table 4 shows that more than $93 \%$ of respondents considered that the expressions $2 a-b, a b, a+3$ and $a \geq$ $b$ always made sense when $a$ and $b$ were real numbers. All the respondents had many years of experience in working with real numbers and were able to make sense of expressions with pronumerals standing for real numbers. Most of the topics in the primary and secondary schools' mathematics involve the use of real numbers and thus the respondents should have more experiences in working with real numbers in comparison with vectors. However, it was interesting to note that $94 \%$ of University 1 respondents incorrectly interpreted that $a \geq b$ always made sense when $a$ and $b$ were real numbers. These students might have interpreted it spontaneously as for any $a$ they can always get a $b$ that was always smaller or equal to $a$. This seems like a plausible interpretation at this 
Table 4. Students' conceptions of real numbers and vectors. Percentage of respondents agreeing that the expression always makes sense (University 1, $\mathrm{n}=86$; University 2, $\mathrm{n}=30$ )

\begin{tabular}{ccccc}
\hline \multirow{2}{*}{ Context } & \multicolumn{2}{c}{$\boldsymbol{a}$ and $\boldsymbol{b}$ real numbers } & \multicolumn{2}{c}{$\boldsymbol{a}$ and $\boldsymbol{b}$ vectors in $\mathbb{R}^{\mathbf{3}}$} \\
\cline { 2 - 5 } & University $\mathbf{1}(\%)$ & University $\mathbf{2}(\%)$ & University $\mathbf{1}(\%)$ & University $\mathbf{2}(\%)$ \\
\hline $\mathbf{2} \boldsymbol{a}-\boldsymbol{b}$ & 99 & 97 & 67 & 83 \\
\hline $\boldsymbol{a} \boldsymbol{b}$ & 98 & 97 & 57 & 50 \\
\hline $\boldsymbol{a}+\mathbf{3}$ & 97 & 97 & 14 & 7 \\
\hline $\boldsymbol{a} \geq \boldsymbol{b}$ & 94 & 67 & 10 & 13 \\
\hline
\end{tabular}

$$
\begin{aligned}
\vec{a} & =(1,2,3) \\
\vec{b} & =(2,3,4) . \\
\vec{a} \cdot \vec{b} & =1 \times 2+2 \times 3+3 \times 4 \\
& =2+6+12 . \\
& =20 .
\end{aligned}
$$

Figure 3. A student's written response for $a \cdot b$

particular instance. For the students, this expression does make sense in real numbers although it is not correct. A more complicated alternate interpretation was $a \geq b$ cannot be always correct for any real values of $a$ and $b$. As an illustration, if $a=8$ and $b=5$ then $a \geq b$ is correct but when $a=6$ and $b=9$ then $a \geq b$ is not correct thus $a \geq$ $b$ cannot be always correct without any condition. On the other hand, 67\% University 2 respondents incorrectly interpreted this item. At this particular instance, there was a possibility that the respondents did not understand the question properly. Some of them might have interpreted it as for any $a$ we can always get a $b$ that was always smaller or equal to $a$.

When $a$ and $b$ are vectors in $\mathbb{R}^{3}, 67 \%$ of University 1 respondents interpreted correctly that $2 a-b$ always made sense. We expected more students to give the correct response for this expression because these students should have met many similar examples in their University's lecture notes and their exercises but we don't have extra data to explain this phenomenon. Again, University 2 had a higher percentage of correct response for this item which was $83 \%$. In another instance, $57 \%$ of University 1 respondents conceived that $a b$ always made sense with $a$ and $b$ vectors in $\mathbb{R}^{3}$ and this was incorrect. In comparison with University 2, 50\% of University 2 respondents gave incorrect response for this item. When the respondents were asked to give an example for $a b$ with $a$ and $b$ vectors in $\mathbb{R}^{3}$, most of them could give a specific example as shown in Figure 3. These respondents conceived $a b=a \cdot b$ most probably due to their prior experience in real numbers where it is common for the students to meet $\times$ which then "fades" to · before "disappearing" as when $a$ is written next to $b$ multiplication is considered to be implicit. In addition, $4 !=4 \cdot 3 \cdot 2 \cdot 1$ with the dot carrying the meaning as multiplication. This can be regarded as a problematic conception in meaning because $a \cdot b$ with $a$ and $b$ vectors in $\mathbb{R}^{3}$ is called as the dot product of $a$ and $b$ but not $a$ multiplied by $b$. A further conceptual hurdle must be overcome when the students go on to meet $\times$ in the context of vectors where it signifies the vector product. In the vector context students must still be alert for implicit multiplication of scalars. These respondents did not take into account the changes in meaning between the two different contexts of real numbers and vectors thus they just applied the dot product formula to get the answer. Additionally the term "product" might also lead them to conceive $a \cdot b$ as an ordinary multiplication such as the multiplication in real numbers. Gray and Tall (1994) used the notion of procept to think of a particular symbol as a process and a concept. In this respect, the symbol $(\cdot)$ in the real numbers context can be conceived as the process (of multiplication) of two real numbers and the concept (of product). On the other hand, the notion of dot product in vectors can mislead the students to conceive it as if it is a multiplication in real numbers. As a consequence, the respondents were not alert to the changes of meaning. Furthermore, in terms of operation, the computation of $a \cdot b$ in vector is similar with the multiplication of two algebraic expressions with ordinary pronumerals but with the need to remember the result of dot products for parallel and orthogonal vectors: $i \cdot i=1, j \cdot j=1, k \cdot k=1$ and $i$. $j=0, i \cdot k=0, j \cdot k=0$. As an illustration: 
Table 5. Analysis of Subject 1 lecture notes related to Survey 2

\begin{tabular}{|c|c|c|c|}
\hline Context & $a, b$ real numbers & $a$ and $b$ vectors in $\mathbb{R}^{3}$ & Possible problematic conception(s) \\
\hline $2 a-b$ & $\begin{array}{l}\text { Students have learnt this } \\
\text { prior taking Subject } 1\end{array}$ & $\begin{array}{l}\text { Addressed in the lecture notes and had } \\
\text { similar problems for exercises }\end{array}$ & \\
\hline$a b$ & $\begin{array}{l}\text { Students have learnt this } \\
\text { prior taking Subject } 1\end{array}$ & $\begin{array}{l}\text { Lecture notes only addressed dot product as } \\
a \cdot b \text { but not multiplication of vectors as } a b \text {. } \\
\text { No multiplication of vectors as } a b \text { in } \\
\text { exercises (new situation) }\end{array}$ & $\begin{array}{l}\text { Multiplying vector by scalar. } \\
\text { Multiplication of vectors (i.e. dot product) } \\
\text { might be conceived as similar with the } \\
\text { multiplication of real numbers due to the } \\
\text { similarity in syntax }\end{array}$ \\
\hline$a+3$ & $\begin{array}{l}\text { Students have learnt this } \\
\text { prior taking Subject } 1\end{array}$ & $\begin{array}{l}\text { Not addressed in the lecture notes and no } \\
\text { similar problems for exercises (new situation) }\end{array}$ & \\
\hline$a \geq b$ & $\begin{array}{l}\text { Students have learnt this } \\
\text { prior taking Subject } 1\end{array}$ & $\begin{array}{l}\text { Not addressed in the lecture notes and no } \\
\text { similar problems for exercises (new situation) }\end{array}$ & $\begin{array}{l}\text { Real numbers are ordered thus some of } \\
\text { the respondents might conceive vectors } \\
\text { are ordered as well. }\end{array}$ \\
\hline
\end{tabular}

if $a=2 i+j+3 k$ and $b=i+2 j+k$

then $a \cdot b=2 i \cdot i+4 i \cdot j+2 i \cdot k+j \cdot i+2 j \cdot j+j \cdot k+3 k \cdot i+6 k \cdot j+3 k \cdot k$.

Finally this can be simplified to $a \cdot b=2+2+3$.

Figure 3 shows a written response from one of the respondents. While the materiality is different the syntax is similar to multiplication in real numbers such as $a \cdot b=(2 x+y+3 z)(x+2 y+z)$ with $a=2 x+y+3 k$ and $b=$ $x+2 y+z$. In this case, $x, y, z$ are three ordinary pronumerals. This typical response shows the similarities in terms of syntax for real numbers and vectors. We explored the association of these two contexts based on the responses of the University 1 respondents and we discovered that $95 \%$ of the respondents who felt that $a b$ always made sense with $a$ and $b$ vectors in $\mathbb{R}^{3}$ also felt that $a b$ always made sense with $a$ and $b$ as real numbers. It can be inferred that these students did sense the similarities in the way of performing the multiplication of real numbers and the dot product.

Among University 1 respondents, $14 \%$ interpreted incorrectly the item $a+3$ when $a$ is a vector. In this item the meaning and syntax of $a$ as a vector in $\mathbb{R}^{3}$ is obscured by the materiality. Only $7 \%$ of University 2 respondents gave an incorrect response for this item. In another instance, $10 \%$ of University 1 respondents gave an incorrect response for the item $a \geq b$ when $a$ and $\mathrm{b}$ were vectors. Similarly, $13 \%$ of University 2 respondents also responded wrongly for this item. While the materiality is different, students may have brought to mind the lengths or magnitudes of $a$ and $b$. These findings also alerted us to the potential effect of prior learning in making sense of mathematics and they were consistent with Martinez-Planell, Trigueros and McGee (2015), Martinez-Planell and Trigueros (2012), Trigueros and Martinez-Planell $(2011,2010)$ who concluded that students' difficulties with multivariable graphing could be due to familiar symbols such as $x^{2}$ that arose from previous learning.

When comparing the results shown in Tables 4, we can notice that University 2 respondents had a higher percentage of correct responses for all the correct items and a lower percentage of incorrect responses for all those incorrect items except for item $a \geq b$ when $a$ and $\mathrm{b}$ were vectors. We analysed the Subject 1 and Subject 2 lecture notes to see if there were differences that might account for the student responses.

Based on Tables 5 and 6, we can see that there were two potentially problematic conceptions that were not addressed explicitly in the lecture notes, in particular the expression $a b$ in the context of vectors and $a \geq b$ when $a$ and $b$ are vectors. As suggested in the previous paragraph the similarity of syntax for the multiplication of real numbers and the multiplication of vectors (i.e. dot product) means respondents might easily get confused when changing between these two contexts. 
Table 6. Analysis of Subject 2 lecture notes related to Survey 2

\begin{tabular}{|c|c|c|c|}
\hline Context & $a, b$ real numbers & $a$ and $b$ vectors in $\mathbb{R}^{3}$ & Possible problematic conception(s) \\
\hline $2 a-b$ & $\begin{array}{l}\text { Students have learnt this } \\
\text { prior taking Subject } 2\end{array}$ & $\begin{array}{l}\text { Addressed in the lecture notes and had similar } \\
\text { problems for exercises }\end{array}$ & \\
\hline$a b$ & $\begin{array}{l}\text { Students have learnt this } \\
\text { prior taking Subject } 2\end{array}$ & $\begin{array}{l}\text { Lecture notes only addressed dot product as } \\
a . b \text { but no multiplication of vectors as } a b \text {. No } \\
\text { multiplication of vectors as } a b \text { in exercises } \\
\text { (new situation) }\end{array}$ & $\begin{array}{l}\text { Multiplying vector by scalar. } \\
\text { Multiplication of vectors (i.e. dot product) } \\
\text { might be conceived as similar with the } \\
\text { multiplication of real numbers due to the } \\
\text { similarity in syntax }\end{array}$ \\
\hline$a+3$ & $\begin{array}{l}\text { Students have learnt this } \\
\text { prior taking Subject } 2\end{array}$ & $\begin{array}{l}\text { Not addressed in the lecture notes and no } \\
\text { similar problems for exercises (new situation) }\end{array}$ & \\
\hline$a \geq b$ & $\begin{array}{l}\text { Students have learnt this } \\
\text { prior taking Subject } 2\end{array}$ & $\begin{array}{l}\text { Not addressed in the lecture notes and no } \\
\text { similar problems for exercises (new situation) }\end{array}$ & $\begin{array}{l}\text { Real numbers are ordered thus some of the } \\
\text { respondents might conceive vectors are } \\
\text { ordered as well. }\end{array}$ \\
\hline
\end{tabular}

\section{CONCLUSION}

The research data reported in this paper was analysed to first identify students' problematic conceptions related to symbols in their undergraduate mathematics subject, next to make a conjectures as to which aspects of the symbolic expression may cause the problem and finally consider whether the lecture notes provided to them draw attention to these potential problems. As mentioned above, Chin (2013) suggests that humans make sense of mathematics by building on their conceptions. Some students may not be aware of problematic conceptions that arise if links to previous understandings do not take into account contexts. Based on this data there is evidence that respondents' incorrect responses may be due to conceptions developed appropriately in other contexts but which become problematic if applied, without refinement, in a changed mathematical domain or context. Typically, materially, the symbols look the same but, in the new context the meaning and sometimes the syntax has changed. We see an example of this in the respondents' interpretation of $\square^{-1}$ and confusion between reciprocal and inverse. Similarly, we see a problematic conception when working with real numbers and vectors.

When the use of a particular symbol has changed due to a change of domain or context then this needs to be addressed explicitly in the lecture notes so that the learners will be alerted to the potentially problematic conceptions in the new context. Some students who practice more exercises and read more mathematical examples or texts may have a higher chance of realising the changes of meaning. From the earliest years on it may be valuable for all students to establish a habit of mind to include a statement about domain or context in mathematical descriptions and definitions. This should draw attention to the fact that symbols that have the same materiality may not always have the same syntax or meaning. For example: (context) $x^{-1}=\frac{1}{x}$ when $x$ is a pronumeral OR (domain) $-a<x<a$ when $a$ is a real number. The result of this study is consonant with Thompson, Cheepurupalli, Hardin, Lienert and Selden (2010) which suggests that students often attach imprecise meanings to mathematical symbols. The framework of supportive and problematic conceptions was able to extend the work of Thompson et al. (2010) by tracing the possible root causes of these imprecise meanings.

The limitation of the study is its research instrument i.e. questionnaires. Some mathematical items of the questionnaires may be interpreted differently by different respondents. On top of that, the quality of the collected data is dependent on how serious the respondents are in answering the given items. The goal of this study is not to generalize but rather to provide a brief summary of the samples and the performed measures. The findings reported in this paper indicate that to help learners bridge the transition to different contexts and mathematical domains, even at the university level, lecture notes need to be developed in a way that will flag possible problematic conceptions. The accumulation of problematic conceptions may seriously impede future learning. Mathematics teachers at all levels should have a "habit of mind" to consider context as part of any description and we posit that mathematical context is too often taken for granted. Asking students relevant questions can be a way to help students to be aware of the changes of meaning that are due to the changes of context.

\section{ACKNOWLEDGEMENTS}

The research was funded by the Australian Research Council: DP150103315. At the time the research for this paper was conducted, Dr Chin was a Visiting Fellow at the University of Melbourne. We wish to thank all the members of the research team and the participants who generously gave of their time and insights. 


\section{REFERENCES}

Bardini, C., \& Pierce, R. (2015). Assumed knowledge: the challenge of symbols. International Journal of Innovation in Science and Mathematics Education, 23(1), 1-9.

Bardini, C., Pierce, R., \& Vincent J. (2015). Contemplating symbolic literacy in first year mathematics students. In M. Marshman, V. Geiger \& A. Bennison (Eds.), Mathematics Education in the Margins: Proceedings of the 38th annual conference of the Mathematics Education Research Group of Australasia, 77- 84.

Chin, K. E. (2013). Making sense of mathematics: supportive and problematic conceptions with special reference to trigonometry (Unpublished doctoral thesis). University of Warwick, England. Retrieved from http:/ / wrap.warwick.ac.uk/58403/

Chin, K. E. (2014). Supportive and problematic aspects in mathematical thinking over the longer term. In S. Oesterle, C. Nicol, P. Liljedahl, \& D. Allan (Eds.), Proceedings of the 38th Conference of the International Group for the Psychology of Mathematics Education and the 36th Conference of the North American Chapter of the Psychology of Mathematics Education, 6, 41. Vancouver, Canada: PME.

Chin, K. E., \& Tall, D. O. (2012). Making sense of mathematics through perception, operation and reason: The case of trigonometric functions. In Tai-Yih Tso (Eds.), Proceedings of the 36th Conference of the International Group for the Psychology of Mathematics Education, 4, 264. Taipei, Taiwan: PME.

Chubb, I., Findlay, C., Du, L., Burmester, B., \& Kusa, L. (2012). Mathematics, engineering and science in the national interest. Commonwealth of Australia. Retrieved from http://www.chiefscientist.gov.au/wpcontent/uploads/Office-of-the-Chief-Scientist-MES-Report-8-May-2012.pdf

Gray, E. M., \& Tall, D. O. (1994). Duality, ambiguity \& flexibility in successful mathematical thinking. In F. Furinghetti (Ed.), Proceedings of the $15^{\text {th }}$ Conference for the International Group for the Psychology of Mathematics Education, 2, 72-79.

Herbel-Eisenmann, B., \& Wagner, D. (2007). A framework for uncovering the way a textbook may position the mathematics teacher. For the Learning of Mathematics, 27(2), 8-14.

Leron, U., \& Hazzan, O. (2006). The rationality debate: Application of cognitive psychology to mathematics education. Educational Studies in Mathematics, 62, 105-126. https:/ / doi.org/10.1007/s10649-006-4833-1

Lima, R. N., \& Tall, D. (2008). Procedural embodiment and magic in linear equations. Educational Studies in Mathematics, 67(1), 3-18. https:/ / doi.org/10.1007/s10649-007-9086-0

Martinez-Planell, R., \& Trigueros, M. (2012). Students' understanding of the general notion of a function of two variables. Educational Studies in Mathematics, 81(3), 365-384. https:/ / doi.org/10.1007/s10649-012-9408-8

Martinez-Planell, R., Trigueros, M., \& McGee, D. (2015). On students' understanding of the differential calculus of functions of two variables The Journal of Mathematical Behavior, 38, 57-86. https:/ / doi.org/10.1016/j.jmathb.2015.03.003

National Council of Teachers of Mathematics (2000). Principles, standards and expectations: Principles and standards for school mathematics.

National Council of Teachers of Mathematics (2009). Focus in High School Mathematics: Reasoning and Sense Making.

Pierce, R., \& Bardini, C. (2016, July). Déjà vu in mathematics: what does it look like? Paper presented at the 13th International Congress on Mathematical Education Hamburg, Germany.

Pimm, D. (1991). Communicating mathematically. In K. Durkin, \& B. Shire (Eds.), Language in Mathematical Education: Research and Practice, 17-23.

Quinnell, L., \& Carter, M. (2012). Greek or not: the use of symbols and abbreviations in mathematics. Australian Mathematics Teacher, 68(2), 34-40.

Serfati, M. (2005). La révolution symbolique. La constitution de l'écriture symbolique mathématique. Paris. Pétra.

Sfard, A. (1991). On the dual nature of mathematical conceptions: Reflections on processes and objects as different sides of the same coin. Educational Studies in Mathematics, 22, 1-36. https:/ / doi.org/10.1007/BF00302715

Shepherd, M., Selden, A., \& Selden, J. (2012). University students' reading of their first-year mathematics textbook. Mathematical Thinking and Learning, 14(3), 226-256. https:/ / doi.org/10.1080/10986065.2012.682959

Sherin, B. L. (1996). The symbolic basis of physical intuition: A study of two symbol systems in physics instruction (Unpublished doctoral dissertation).

Singhal, P. (2018, March 24). HSC students abandoning high-level subjects. The Sydney Morning Herald. Retrieved from https://www.smh.com.au/education/hsc-students-abandoning-high-level-subjects-20180323p4z5yn.html 
Smith, J. P., DiSessa, A. A., \& Roschelle, J. (1993). Misconceptions reconceived: A contructivist analysis of knowledge in transition. The Journal of the Learning Sciences, 3(2), 115-163. https:/ / doi.org/10.1207/s15327809j1s0302_1

Sullivan, P., \& Mousley, J. (2005). Quality mathematics teaching: Describing some key components. Mathematics Education Research Journal, 6(1), 4-22. https:/ / doi.org/10.1007/BF03217259

Tall, D. O. (2013). How humans learn to think mathematically.

Tall, D. O., \& Vinner, S. (1981). Concept image and concept definition in mathematics, with special reference to limits and continuity. Educational Studies in Mathematics, 12, 151-169. https:/ / doi.org/10.1007/BF00305619

Thompson, P. W., Cheepurupalli, R., Hardin, B., Lienert, C., \& Selden, A. (2010, March). Cultivating Symbol Sense in Your Calculus Class. Paper presented at the IM\&E Workshop, San Diego, CA. Retrieved from http:/ /ime.math.arizona.edu/2009-10/Pamphlets/Symbols.pdf

Trigueros, M., \& Martínez-Planell, R. (2010). Geometrical representations in the learning of two-variable functions. Educational Studies in Mathematics, 73(1), 3-19. https:/ / doi.org/10.1007/s10649-009-9201-5

Trigueros, M., \& Martínez-Planell, R. (2011). How are graphs of two variable functions taught? In L. R. Wiest \& T. Lamberg (Eds.). Proceedings of the 33rd Annual Meeting of the North American Chapter of the International Group for the Psychology of Mathematics Education. Retrieved from http:/ / pegasus.uprm.edu/rmplanell/articulo5.pdf

Victorian Curriculum Assessment Authority (2016). VCE mathematics Study Design. Retrieved from http://www.vcaa.vic.edu.au/Documents/vce/mathematics/MathematicsSD-2016.pdf

\section{http://www.ejmste.com}

